\title{
As etapas da carreira docente e o processo de formação continuada de professores de Educação Física ${ }^{1}$
}

CDD. 20.ed. 371.12

796.017

\author{
Fernanda ROSSI* \\ Dagmar HUNGER ${ }^{* * *}$
}

*Universidade Estadual

Paulista- Rio Claro.

* Universidade Estadual

Paulista-Bauru.

\section{Resumo}

Nesta pesquisa, de natureza qualitativa, objetivou-se analisar os significados atribuídos por professores de Educação Física escolar à relação entre a formação continuada e as etapas do desenvolvimento profissional. Foram realizadas entrevistas semiestruturadas com oito professores da rede pública estadual de Bauru/SP. Os dados foram analisados seguindo o referencial teórico de HUBERMAN (2000), relativamente ao conceito de ciclos de vida profissional, e constatou-se que assim como ocorre com outros fatores da carreira docente, em relação à dimensão da formação continuada os professores também apresentam necessidades diferentes em cada momento profissional. Em sintese conclui-se: na fase de iniciação à docência buscam ações formativas para aprimorar a prática pedagógica; fase de estabilização: solucionar os problemas do contexto educacional e disseminar os conteúdos acadêmicos entre os professores escolares; fase de diversificação: embasamento para trabalhar novos conteúdos e atualização constante diante das novidades educacionais; serenidade/ desinvestimento: necessidade de frequentar atividades formativas em espaços diferentes da escola.

UnITERMOS: Formação docente; Ciclos de desenvolvimento profissional; Educação física escolar.

\section{Introdução}

Ao tratar da profissão docente na atualidade enfatiza-se, em praticamente todos os contextos escolares, a questão da formação continuada de professores, sendo concebida como uma tarefa coletiva entre professores, gestores, pesquisadores e outros atores do campo educacional. Essa dimensão da formação constitui-se num processo contínuo e ininterrupto, que percorre toda a trajetória profissional do professor, sempre com o intuito de aprimorar a sua ação pedagógica e desenvolver a sua profissionalidade docente, a sua identidade.

Ressaltam pesquisadores, como DEMO (2002, 2004) e VASCONCELLOS (2004), que o fundamental para o profissional da educação é manter-se bem formado, o que implica em, além de ter tido um bom embasamento inicial, alimentar de modo contínuo a sua formação, dada a complexidade e dinamicidade do ato de ensinar. Todo professor deve compreender sua formação como um "continuum" que se estende por toda a vida profissional (FERREIRA, 2006; GÜNther \& Molina Neto, 2000; Marcelo García, 1995; Pimenta, 2000; Rangel-Betti, 2001).
Para pensar em modelos de formação que promovam o desenvolvimento profissional do docente e mudanças na prática pedagógica, CANDAU (1997) enfatiza três eixos de investigação apontados pelos profissionais da educação como imprescindíveis: definir a escola como o "locus" da formação; valorizar os saberes experienciais dos professores; e, atentar para as diferentes etapas do desenvolvimento profissional docente.

No que se refere ao último eixo, destaca-se que o professor, durante sua vida profissional, percorre diferentes momentos e fases, apresentando características que diferencia o corpo docente em cada momento da carreira, o que HubERMAN (2000) denomina como ciclos de vida profissional do docente.

Neste sentido, o problema norteador da pesquisa consistiu em questionar e responder se as necessidades formativas em cada período profissional são as mesmas para os professores. Diante disto, nesta pesquisa objetivou-se analisar os significados atribuídos pelos professores de Educação Física escolar a um dos elementos que compóem a tríade da formação contínua: as etapas do desenvolvimento profissional. 
Portanto, constituiu a preocupação dessa análise a hipótese de que as prioridades de formação variam de acordo com o decorrer da carreira assim como ocorre com outros fatores profissionais, encontrados pelo autor como expressivos em cada etapa docente. Seguindo a trajetória profissional discutida por HUBERMAN (2000), tais fatores podem ser sintetizados como as preocupaçōes que o professor tem consigo mesmo no início da carreira e, no decorrer da mesma, os desencontros entre os ideais e as realidades que vão surgindo, o sentimento de competência crescente e segurança, a necessidade de experimentação e diversificação, a motivação elevada, a busca de desafios, até chegar ao final da carreira, geralmente, com o sentimento de conformismo com sua prática e/ou serenidade profissional.

Pretendeu-se averiguar a relação da formação continuada em Educação Física com o desenvolvimento da carreira docente, a partir das perspectivas de um grupo de oito professores de Educação Física da rede pública estadual de Bauru/SP. Entende-se que ao identificar as necessidades de formação manifestadas pelos professores em cada etapa da carreira, o estudo poderá apresentar como contribuiçôes indicativos para (re)pensar as ações formativas, de modo que correspondam mais adequadamente ao momento vivido pelos docentes em sua profissão.

\section{Formação continuada: a busca por novos delineamentos}

Ao longo das últimas décadas, a formação continuada de professores vem ocupando lugar significativo nos debates educacionais contemporâneos, revelando-se como uma preocupação por parte do poder público, entre as universidades e centros de pesquisa (MEDIANO, 1997) e entre os docentes que estão atuando na escola (GÜNTHER \& Molina Neto, 2000).

Chakur (2000, p.82) coloca que a razão mais comumente utilizada para justificar a necessidade da formação continuada apoia-se nos benefícios da atualização dos conteúdos básicos para uma melhor correspondência com as condições escolares, suprindo, ao mesmo tempo, as deficiências da formação inicial. Mas, concorda-se com a autora ao explicar que a formação continuada é justificada por uma razão muito mais profunda que se relaciona com a "própria natureza da prática docente que, enquanto um fazer histórico, não se mostra pronto e acabado, pois se encontra sempre vinculado a um saber". A formação continuada contribui para a modificação da profissionalização do professor e desenvolve domínios necessários à sua qualificação, como também atua no exame de possíveis soluçōes para os problemas reais do ensino.

Não obstante, o cenário atual da formação contínua evidencia que as práticas não têm contribuído efetivamente para a transformação das aulas e para o desenvolvimento profissional dos professores. As ações vêm sendo implementadas de formas variadas, dentre as quais se destaca a ênfase na formação institucionalizada, com a presença dos professores nos centros universitários (CANDAU, 1997; NóvOA, 1999); assim como a realização de cursos de atualização de conteúdos, eventos e palestras que pouco contribuem para a prática docente (DEMO, 2002;
Pimenta, 2000). Tem-se desconsiderado o professor como um sujeito ativo de seu próprio desenvolvimento, suas experiências adquiridas no exercício da profissão docente e os conhecimentos construídos nas suas histórias de vida.

Projetando um novo direcionamento para a formação continuada e em resposta aos modelos de formação que não apresentam resultados efetivos para a prática pedagógica, uma série de buscas, reflexões e pesquisas estão sendo orientadas no sentido de construir uma nova concepção de formação continuada (CANDAU, 1997).

Para MARIN (1995) convém abordar o "continuum" de formação de professores como educação permanente, formação continuada e/ou educação continuada por serem estes os termos que mais apropriadamente representam os significados da formação no contexto educacional, pois apresentam como eixo da formação o conhecimento.

Trata-se de colocar como eixo o conhecimento, centro da formação inicial ou básica, de formação continuada; de realizar e usar pesquisas que valorizem o conhecimento dos profissionais da educação e tudo aquilo que eles podem auxiliar a construir. É o conhecimento, ainda, estabelecido como fulcro das novas dinâmicas interacionistas das instituiçōes para a valorização da educação e a superação de seus problemas e dificuldades (Marin, 1995, p.17-8).

Pode-se sintetizar que esses termos trazem como concepçôes a ideia de uma educação como processo prolongado pela vida toda e o significado de atividade conscientemente proposta, direcionada para a mudança. Articulam-se aos aspectos institucionais, visando à 
implementação desses processos também no "locus" do próprio trabalho cotidiano de maneira contínua, transformando-se numa "verdadeira prática social de educação mobilizadora de todas as possibilidades de todos os saberes dos profissionais" (MARIN, 1995, p.18).

NóvoA (1995) ao afirmar que a formação tem ignorado tanto o desenvolvimento pessoal do professor, quanto a articulação entre a formação e os projetos das escolas, constata que para a formação adquirir como eixo de referência o desenvolvimento profissional implica em considerar três dimensōes estratégicas para a formação: produzir a vida do professor (desenvolvimento pessoal), produzir a profissão docente (desenvolvimento profissional) e produzir a escola (desenvolvimento organizacional). Essas são estratégias eficazes para adquirir como eixo de referência o desenvolvimento dos professores na dupla perspectiva do professor individual e do coletivo docente (NóvoA, 1992, 1995).

Para produzir a vida do professor, NóvoA (1992, 1995) propõe a formação na perspectiva críticoreflexiva, que forneça aos professores os meios de um pensamento autônomo e conduza a dinâmicas de autoformação participada, possibilitando a troca de experiências, a partilha dos saberes e a produção desses saberes, transformando o professor no construtor de sua formação.

$\mathrm{O}$ professor deve ser recolocado no centro dos debates educativos, das ações e problemáticas de investigação (NóvOA, 1995, 2000). Assim, produzir a profissão docente implica em:

[...] valorizar paradigmas de formação que promovam a preparação de professores reflexivos, que assumam a responsabilidade do seu próprio desenvolvimento profissional e que participem como protagonistas na implementação das políticas educativas (NóvoA, 1995, p.27).

Formar-se implica ao professor um investimento pessoal, o desenvolvimento de um trabalho livre e criativo sobre trajetórias e projetos, em busca da construção de uma identidade tanto pessoal como profissional. Nias (1991) citado por Nóvoa (1992, 1995, 2000) enfatiza que o professor é a pessoa, assim como uma parte importante da pessoa é o professor.

Urge por isso (re)encontrar espaços de interacção entre as dimensōes pessoais e profissionais, permitindo aos professores apropriar-se dos seus processos de formação e dar-lhes um sentido no quadro das suas histórias de vida (NóvoA, 1995, p.25).

As práticas de formação, ao assumirem como referência as dimensões coletivas, estão contribuindo para a emancipação profissional e para a consolidação de uma profissão autônoma na produção dos seus saberes e valores. Os professores precisam se assumir como produtores da sua própria profissão (NóvOA, 1992, 1995).

Mas, "falar de formação de professores é falar de um investimento educativo dos projectos de escola" (NóvoA, 1992, p.7). Diante disto, não basta formar ou mudar o profissional, é preciso também intervir no ambiente em que sua ação é colocada em prática. Para tanto, o desenvolvimento profissional deve articular-se com os projetos da escola. Produzir a escola é elementar, pois nenhuma inovação pode ocorrer sem uma mudança no âmbito das organizaçôes escolares e do seu funcionamento. $\mathrm{O}$ desafio consiste em conceber a escola como um ambiente educativo, onde trabalhar e formar não sejam atividades distintas, concebendo a formação como um processo permanente (NóvOA, 1992, 1995).

Nessa perspectiva, NóvoA (1999) destaca a contribuição das abordagens autobiográficas, das práticas de escrita pessoal e coletiva e do estímulo a uma atitude de investigação para as práticas de formação continuada, que deveriam fazer parte de uma concepção abrangente de formação de professores como meio de transformar a experiência em conhecimento, formalizando um saber profissional de referência.

Adotando esta mesma concepção, BuENo (1998) aponta para o uso da pesquisa em colaboração e de narrativas autobiográficas em superação aos modelos tradicionais de formação contínua, com suas imposições de ideias prontas e anulação da experiência passada. $\mathrm{O}$ intuito é justamente trabalhar a memória e a recuperação dessa experiência, tornando o professor pesquisador de sua história de vida, de sua prática docente, dos seus alunos, sendo levado, portanto, a compreender seu contexto e suas interaçóes e a estabelecer novas relações com a docência e o ofício de ensinar.

A respeito do cotidiano escolar, ANDRÉ (1994, p.74) defende o uso da pesquisa etnográfica com ênfase nas situaçóes do dia-a-dia do professor, tendo como objetivo a articulação entre "teoria e prática pedagógica, pesquisa e ensino, reflexão e ação didáticas". Discutir cenas do cotidiano escolar em cursos ou programas de formação e aperfeiçoamento docente pode ser uma excelente alternativa para a articulação teoria-prática. Pode aproximar o professor das situações reais das escolas e permitir a investigação teórica de forma mais orientada e significativa.

A questão essencial não é organizar mais cursos ou ampliar a formação. O que falta, na visão de Nóvoa (1999), é integrar essas dimensões ao cotidiano da profissão docente, fazendo com que elas se tornem parte essencial da definição de cada um como professor, como professora. 
De acordo com os estudos de LiBÂNEO (2002, p.74) as práticas de formação de professores encerram quatro requisitos fundamentais, a saber:

[...] uma cultura científica crítica como suportes teóricos ao trabalho docente; conteúdos instrumentais que assegurem o saber-fazer; uma estrutura de organização e gestão das escolas que propicie espaços de aprendizagem e de desenvolvimento profissional; uma base de convicções ético-políticas que permita a inserção do trabalho docente num conjunto de condicionantes políticos e socioculturais.

Dentre os muitos aspectos a serem considerados nas práticas de formação de professores, GIMENO SACRISTÁN (2002, p.87) é contundente ao afirmar que a questão do "habitus" assume caráter de especial relevância: A formação do professor deve considerar o significado do que P. Bourdieu discutiu há muito tempo, o habitus, como forma de integração entre o mundo das instituições e o mundo das pessoas. O habitus em educação é mais importante do que a ciência e do que os motivos. O habitus é cultura, é costume, é conservadorismo, mas é, também, continuidade social e, como tal, pode produzir outras práticas diferentes das existentes.

Nessa direção, a formação de professores pode desempenhar um papel importante na configuração de uma nova profissionalidade docente (NóvoA, 1992, 1995). É pertinente ressaltar que a profissionalidade docente não se encerra numa qualificação especializada, mas consiste no

[...] acesso à capacidade de resolver problemas complexos e variados pelos seus próprios meios, no quadro de objectivos gerais e de uma ética, sem ser obrigado a seguir procedimentos detalhados concebidos por outros. É pois ser, mais do que numa actividade de execução, capaz de autonomia e responsabilidade (Perrenoud, 1997, p.184).

Para Contreras (2002) a profissionalidade docente implica em três dimensões, três exigências do trabalho de ensinar: a obrigação moral, o compromisso com a comunidade e a competência profissional. A obrigação moral se traduz para os professores na preocupação com o bem estar dos alunos e nas implicações éticas do seu trabalho, exigindo-lhes consciência sobre o sentido do que é desejável educativamente. $\mathrm{O}$ compromisso com a comunidade requer que as práticas profissionais não se constituam isoladamente, mas partilhadas, uma vez que a educação é para os professores uma ocupação socialmente encomenda e responsabilizada publicamente. Tal exigência ultrapassa a categoria profissional, estendendo a responsabilidade pública para a comunidade que deve, também, participar das decisões relacionadas ao ensino. Por fim, a competência profissional transcende o sentido técnico dos recursos didáticos: trata-se de competências profissionais complexas que articulam habilidades, princípios e a consciência da importância do seu trabalho e de suas consequências. Ou seja, uma competência profissional coerente com a obrigação moral e o compromisso com a comunidade.

Constata-se que a formação continuada vem procurando caminhos de desenvolvimento, de renovação. Está deixando de ser concebida na perspectiva da acumulação de cursos, conhecimentos ou técnicas e passando a ser concebida como um processo de reflexão das práticas e de (re)construção permanente de uma identidade pessoal e profissional (CANDAU, 1997; NóvOA, 1995).

As tendências aqui explicitadas, trazidas de autores estudiosos do tema, representam um avanço considerável para a formação contínua, ainda que se configure como um processo em construção. É preciso que os professores sejam capazes de refletirem sobre a sua própria profissão, encontrando modos de formação e de trabalho que lhes permitam atuar como principal agente da sua formação, assumindo-se como sujeito do seu desenvolvimento, articulando de forma indissociável os projetos profissionais, pessoais e organizacionais. Todavia, é preciso ressaltar que a motivação para com a profissão não é uma peculiaridade individual, unicamente de natureza intrínseca, mas decorrente de fatores extrínsecos, sobretudo. Para os professores, os fatores extrínsecos que interferem na sua profissão englobam a desvalorização profissional, a precarização do trabalho docente, a violência presente nos ambientes escolares, a hierarquia e burocratização a que estão submetidos, dentre outros.

\section{Etapas do desenvolvimento profissional docente}

Os eixos apontados pelos profissionais da educação para o desenvolvimento das ações de formação continuada implicam em estabelecer a escola como o "locus" principal da formação, valorizar os saberes experienciais dos professores e considerar as diferentes etapas do desenvolvimento profissional docente (CANDAU, 1997), conforme já citado. 
No cotidiano do professor na escola "ele aprende, desaprende, reestrutura o aprendido, faz descobertas" (CANDAU, 1997, p.57). E preciso, portanto, estabelecer a escola como o "locus" da formação a ser privilegiado.

O segundo eixo da formação continuada consiste em adotar como referência fundamental para o seu desenvolvimento, o reconhecimento e a valorização dos saberes docentes, especialmente os saberes da experiência, "núcleo vital do saber docente, e a partir do qual o professor dialoga com as disciplinas e os saberes curriculares" (CANDAU, 1997, p.59; TARDIF, 2002).

Por fim, o terceiro eixo baseia-se em considerar as diferentes etapas do desenvolvimento profissional do docente nas práticas de formação continuada, dada a complexidade do ciclo profissional dos professores. Em diferentes momentos do exercício profissional, os professores enfrentam problemas, têm necessidades e perspectivas diversas. O ciclo de vida profissional representa um impacto considerável nas concepções e estratégias de formação continuada (CANDAU, 1997).

Para Huberman (2000), o desenvolvimento da carreira docente para alguns professores pode acontecer de modo tranquilo, enquanto para outros pode estar permeado de dúvidas, angústias, regressões. $\mathrm{O}$ ciclo profissional docente revela-se, assim, como um processo complexo. De acordo com o autor, o desenvolvimento da carreira constitui-se em "[...] um processo e não em uma série de acontecimentos. Para alguns, este processo pode parecer linear, mas para outros, há patamares, regressões, becos sem saída, momentos de arranque, descontinuidades" (HuBERMAN, 2000, p.38).

MarCelo GarCía (1999) chama a atenção que a investigação referente ao ciclo vital dos professores realizada por HubERMAN (2000) talvez tenha sido a mais difundida nos últimos anos, trazendo, diz CANDAU (1997) contribuições significativas para o estudo da formação continuada de professores.

Em seus estudos, o autor encontrou sequênciastipo no desenvolvimento da carreira do professor e as classificou em etapas básicas, de acordo com os anos de carreira, lembrando que estas não devem ser tomadas como fases estáticas ou lineares, mas concebidas por meio de uma relação dialética: entrada na carreira (um a três anos de docência): fase de sobrevivência, descoberta e exploração; estabilização (quatro a seis anos): sentimento de competência e pertença a um corpo profissional; diversificação ou questionamentos (sete a 25 anos): estágio de experimentação, motivação, busca de novos desafios el ou momento de questionamentos e reflexão sobre a carreira; serenidade e distanciamento afetivo elou conservadorismo e lamentaçôes (25 a 35 anos): pode levar ao conformismo ou ao ativismo; e, por fim, fase de desinvestimento, recuo e interiorização (35 a 40 anos): pode ser sereno ou amargo.

CavaCo (1999) também estudou o desenrolar da vida pessoal e profissional de docentes. A autora apresenta como principais constatações que o início da carreira representa insegurança, instabilidade, caracterizando-se, especialmente, como fase de sobrevivência; que a estrutura da carreira docente não considera as necessidades intrínsecas de desenvolvimento pessoal, fazendo com que a carreira não se ajuste à evolução da estrutura da vida, mas identificou duas linhas orientadoras, uma caracterizada pela continuidade e aceitação e outra pela inovação e diversidade; e, por fim, que a felicidade na profissão parece vir do fato do professor aceitar aventuras, riscos, desafios, prosseguir grandes metas, manter certo grau de liberdade, reconhecer o valor dos acertos e erros a partir da análise da própria experiência, escutar/reconhecer os outros, repensar sua vida e reviver cada dia.

PIÉRON (1996) desenvolveu estudos dos estágios de desenvolvimento profissional de professores de Educação Física. BerLiner (1988) é citado por PiéRON (1996) para situar os professores em diferentes níveis profissionais. Classificou como principiante o estudante e o professor no $1^{\circ}$ ano de atuação, que tem como principal preocupação adquirir experiência. No caso dos professores que se encontram com dois e três anos de experiência, o autor chamou de principiante avançado, fase em que o docente começa a responder ao contexto e a desenvolver certo conhecimento estratégico. Professores de Educação Física com três ou quatro anos de docência e alguns mais experientes podem ser classificados como o professor competente, apresentando como principal característica a capacidade de tomar decisões de forma consciente sobre o que é necessário para o desenvolvimento da aula. A partir dos cinco anos de prática, o professor construiu um expressivo repertório de experiências e possui um sentido mais global da aula, podendo ser chamado de professor eficaz. Após essa fase, o professor assume uma postura de professor expert para o autor. No entanto, segundo sua teoria, somente alguns professores são capazes de atingir esse patamar que implica em ensinar intuitivamente, respondendo às situações escolares com fluidez, quase que inconscientemente, ao menos que surja um problema específico.

Moreira, Nascimento, Sonoo e Both (2010) analisaram o nível de percepção de qualidade de vida no trabalho, baseado no parâmetro socioambiental, o tipo de comportamento referente ao perfil do estilo de 
vida individual, com base no parâmetro individual, e suas associações com os ciclos de desenvolvimento profissional de professores de Educação Física atuantes na rede pública estadual de ensino do Estado do Paraná.

Os autores concluíram, dentre outros, que a maioria dos professores investigados está satisfeita com a qualidade de vida no trabalho. Mas, aspectos negativos foram relacionados à remuneração e compensação, condiçôes de trabalho, integração social na organização do trabalho e espaço total de vida; configurando-se estes em motivos de insatisfação. Ainda,

Ao considerar os ciclos de desenvolvimento profissional, observou-se que aumenta o nível de insatisfação da maioria dos componentes da qualidade de vida no trabalho, excetuando-se os componentes remuneração e compensação e integração social na organização do trabalho (Moreira et al., 2010, p.908-9).

Os autores complementam que os professores mais experientes apresentam comportamentos menos positivos quando se trata do componente atividade física do que os professores em início de carreira. Apontam para a necessidade de desenvolvimento de políticas institucionais de valorização da profissão docente ao longo da profissão, destacando "a implementação de planos de carreira, que contemplem tanto a possibilidade de ganho financeiro quanto o investimento pessoal por meio da capacitação periódica dos professores" (Moreira et al., 2010, p.909).

MARCElO GARCÍA $(1995,1999)$ se refere às distintas fases por que passa o professor no processo de aprender a ensinar como formação inicial, período de iniciação e desenvolvimento profissional. "Convém prestar uma atenção especial ao conceito de desenvolvimento

\section{Metodologia}

\section{Sujeitos}

As principais características da pesquisa qualitativa são: respostas a questôes muito particulares; estudos de contextos sociais que não podem ser quantificados (MinaYO, 2001); amostragem realizada com base numa parte representativa da população da pesquisa, apresentando características semelhantes da população da qual foi extraída. Conforme a autora, ao abordar a questão da amostragem na pesquisa qualitativa, enfatiza que nesta há uma preocupação menor com a generalização, ou melhor, o mais importante é um maior aprofundamento e abrangência da compreensão do fenômeno. Portanto, profissional dos professores", por ser este o que melhor corresponde à concepção atual do professor como um profissional do ensino (1995, p.55, grifos do autor). A noção de desenvolvimento profissional defendida pelo autor traz consigo uma ideia de evolução e de continuidade (superando a justaposição entre formação inicial e aperfeiçoamento dos professores), assim como pressupõe uma valorização dos aspectos contextuais, organizacionais e orientados para a mudança, numa tentativa de superação do caráter individualista nas atividades de formação continuada dos professores, colocando a ênfase na dimensão participativa (ativa) dos professores.

Cabe ressaltar que o desenvolvimento profissional docente não é um processo independente e individual, ocorre na dinâmica das transformaçôes sociais, políticas, econômicas e culturais. É interdependente, portanto, de processos que o desencadeiem.

Como lembra Vigotski (1988) as mudanças pelas quais o homem passa ocorrem na medida em que este é inserido na sociedade, uma vez que tais mudanças dependem das relações estabelecidas com outros sujeitos, com o mundo. Portanto, o desenvolvimento do homem (assim como do ser professor) se dá mediante sua inserção no meio social, cultural e histórico e, assim sendo, embora o corpo profissional apresente semelhanças numa determinada fase da carreira docente, o percurso de cada sujeito/docente tem suas singularidades. CHAKUR (2005, p.399) enfatiza que "não se pode contestar o fato de que as pressões e constrangimentos das condições de trabalho e dos contextos institucional, cultural e histórico deixam marcas nas trajetórias individuais ou no percurso do coletivo de docentes". o critério quantitativo não é o mais significativo, mas a incursão social, ou ainda, a capacidade do pesquisador de identificar e analisar profundamente dados não mensuráveis, como percepções, pensamentos, opiniōes, significados etc. de um determinado grupo de pessoas em relação a um dado problema.

De acordo com a fundamentação teórica explicitada acima, na presente pesquisa foi investigado um grupo composto por oito professores de Educação Física do ensino fundamental e médio, atuantes nas escolas públicas estaduais da cidade de Bauru/SP.

Foi obtido o consentimento livre e esclarecido dos sujeitos, assim como a aprovação no Comitê 
de Ética em Pesquisa para estudos envolvendo seres humanos (Protocolo no 1760/46/01/08).

O grupo de sujeitos foi formado por professores do sexo masculino e feminino, com idades entre 26 e 63 anos. Os professores concluíram a graduação entre os anos de 1973 e 2005 e o tempo de docência na Educação Física escolar variava entre dois anos e meio e 30 anos. Contemplaram-se, também, diferentes níveis de titulação: professores licenciados em Educação Física, licenciados também em Pedagogia e pós-graduados: especialistas e mestres, bem como professores que estão em diferentes etapas da carreira docente (de professores iniciantes a professores experientes), tendo em vista que a formação do professor é entendida como um continuum que percorre toda a sua vida profissional (MARCelo García, 1995; Pimenta, 2000; Rangel-Betti, 2001).

\section{Procedimentos de coleta}

A pesquisa, de natureza qualitativa, teve como instrumento de coleta de dados o recurso das fontes orais. Os documentos gerados, por intermédio da técnica de entrevista semi-estruturada, são resultados da interação entre entrevistador e entrevistado, entre o sujeito e o objeto de estudo, e isso faz com que o pesquisador se afaste de interpretações que venham a separar rigidamente sujeito e objeto de pesquisa (Amado \& Ferreira, 1996).

Para tanto, foi elaborado um roteiro de questōes com a finalidade de nortear a entrevista em busca de relatos relacionados à problemática do estudo, mas que ao mesmo tempo possibilitasse ao entrevistado explorar outros aspectos que julgasse relevante, pois como bem elucida THOMPSON (1992), a coleta de depoimentos pode servir para dar voz a atores sociais.

\section{Procedimentos para análise da dados}

A análise dos relatos dos professores foi pautada pela discussão com o referencial teórico, especialmente o estudo de Huberman (2000) sobre os ciclos de vida profissional na docência, procurando valorizar os entrevistados e suas manifestaçōes, destacando o que cada um poderia trazer de contribuição para o objeto de estudo. Buscou-se apreender os significados emitidos nos depoimentos dos professores com relação a formação continuada e o desenvolvimento da carreira do professor de Educação Física, evidenciando as necessidades e expectativas relacionadas à formação nesse percurso.

O conjunto documental oral é elemento fundamental para compreender e registrar no tempo presente como o problema da formação continuada é enfatizado nas vozes de professores de um determinado grupo, o qual analisado em diálogo com o referencial teórico apresentou-se como uma significativa possibilidade de ampliação do conhecimento desse fenômeno e possibilidades de indicativos para (re)pensar ações formativas.

No próximo tópico inicia-se a análise e discussão dos depoimentos à luz do estudo de Huberman (2000). Tal referencial teórico foi adotado muito mais como uma fonte de inspiração para enriquecer a análise do material empírico (os depoimentos). Avaliou-se que a recorrência a uma perspectiva teórica, não obstante as possíveis limitações, poderia ampliar o potencial de análise, possibilitando uma maior elucidação da complexidade do fenômeno.

Literatura referente aos ciclos de vida profissional na docência é recente - especialmente na área da Educação Física - e requer estudos que aprofundem os acontecimentos comuns e as particularidades da trajetória profissional. Assim como o próprio Huberman (2000) esclarece, o desenvolvimento profissional docente consiste em um processo que não é linear, muito menos idêntico a todos os professores. Além disso, as concepções e ações docentes são, em significativa medida, determinadas pelos contextos micro (a sala de aula, os alunos, a escola...) e macrossociais (políticas públicas, economia, fatores sociais e culturais etc.). Afinal, o professorado está envolvido em contextos complexos, em teias de interdependência que dão origem a configurações das mais variadas (ELIAS, 1980).

Acreditou-se que a capacidade de observação tornar-se-ia mais eficiente e penetrante quando fundamentada conceitualmente por uma determinada teoria, sendo o referencial adotado uma possibilidade de compreensão dos sentimentos e ações dos professores conforme as experiências vivenciadas e a maturidade pessoal e profissional desenvolvida ao longo dos anos. 


\section{O desenvolvimento profissional no processo de formação continuada: perspectivas dos professores de Educação Física escolar}

Em diferentes momentos da carreira os professores revelam necessidades, expectativas, anseios, satisfação ou insatisfação de forma diferente, como explicita Huberman (2000). Os relatos do grupo entrevistado permitiram verificar que os depoentes apresentaram características diferentes de acordo com o momento da profissão que se encontravam. Para elucidá-las, seguem as análises dos resultados em articulação com os ciclos de vida profissional delineados pelo autor.

\section{Entrada na carreira (1-3 anos de carreira)}

HUBERMAn (2000) classifica esta fase como sobrevivência, descoberta e exploração. A sobrevivência se dá entremeio ao choque com o real (confronto inicial com a complexidade profissional), envolvendo as preocupações consigo mesmo, os desencontros entre os ideais e as realidades e o enfrentamento a outras dificuldades do contexto escolar. Já a descoberta traduz o entusiasmo do início de carreira, experimentações e a exaltação pela responsabilidade assumida, por constituir parte de um corpo profissional. Soma-se a estes aspectos a exploração que pode ser fácil ou problemática, sendo limitada, portanto, por questôes de ordem institucional.

Dentre os participantes desse estudo, dois professores encontravam-se nessa fase da carreira docente: o Professor 1, com três anos de docência e o Professor 3 com dois anos e meio de atuação na Educação Física escolar.

No que se refere às concepçóes acerca do desenvolvimento profissional, P1 declarou suas necessidades: "acho que eu preciso ter mais assim, organização no meu trabalho e mais certeza do que eu estou fazendo". Destacou, como pontua HubERMAN (2000), a angústia com relação aos seus ideais e o confronto com a realidade do contexto escolar:

[...] a gente fica angustiado de muita coisa que a gente quer, que a gente espera que os alunos respondam daquela forma ou que a gente espera que a escola seja assim e não, e não atende nossas expectativas [...] a gente vê isso em situaçôes, às vezes, que o aluno faz coisas que a gente não está ensinando ou que não está ajudando em nada, nada, né. Ou a escola, você faz um projeto pra tentar melhorar alguma coisa e não melhora. E, às vezes, você não tem ajuda dos pais. Tem muitos pais que participam, estão preocupados, às vezes não sabem como ajudar. Mas, tem pais que são muito displicentes, relapsos ou chega até o ponto de falar o contrário do que a gente fala aqui [...].

Observou-se, assim, a decepção do professor a respeito das limitações do alcance da função que exerce no sistema educacional:

[...] a confiança que você tinha, que você tem quando você espera que um dia você vai dar aula, né, quando você está na graduação, você vê que... é possível você fazer as práticas, mas a sua parcela de responsabilidade, de influência sobre eles é bem menor do que você imaginava [...] não é por isso que eu perco a esperança, né, mas, você percebe que você é muito pequeno nesse processo todo (P1).

Ao tratar das necessidades relacionadas ao processo de formação continuada, sinalizou o depoente que gostaria de aprimorar-se para ser capaz de construir uma prática em conjunto com seus alunos, uma prática reflexiva e elaborada por todos os envolvidos.

Como contribuição para o seu aprimoramento profissional, reconheceu que participar de práticas de formação continuada facilita o trabalho docente, aumenta o seu aproveitamento e o torna mais eficaz.

Ao ser questionado quanto ao desenvolvimento de sua carreira, outro entrevistado, o Professor 3, relatou que não pretendia atuar na educação básica ao concluir o curso de licenciatura em Educação Física. Iniciou sua atuação profissional na área do treinamento esportivo (preparação física) e em academias de ginástica. Mas, como tais áreas não supriram suas necessidades financeiras decidiu prestar concursos públicos em outros campos profissionais, como na área de educação para o trânsito e policial. Essa postura reflete o que HUBERMAN (2000) descreve como as preocupaçóes consigo mesmo, presentes nessa fase da carreira.

Contudo, após trabalhar nessas duas áreas (educação para o trânsito e policial), o professor acabou optando por inscrever-se em concurso na área da educação, pois concluiu que precisava de um emprego que oferecesse mais segurança para sua família. Foi assim que iniciou sua jornada na Educação Física escolar.

Declarou não saber por quanto tempo continuará na função de professor, mas que enquanto estiver atuando nesse âmbito se dedicará a fazer o seu trabalho com competência, buscando, inclusive por meio da formação contínua, melhorar sua prática pedagógica constantemente. 


\section{Fase de estabilização (4-6 anos)}

Essa fase caracteriza-se como o estágio de consolidação pedagógica, de sentimento de competência crescente e segurança. Ocorre o comprometimento com a carreira docente e aumenta a preocupação com os objetivos didáticos. Considera-se, ainda, como a fase de libertação ou emancipação, em que se acentua o grau de liberdade profissional (HubERMAn, 2000).

Nessa fase da carreira estavam as Professoras 5 e 7; a Professora 5 com quatro anos de docência na Educação Física escolar, enquanto a Professora 7 com cinco anos de experiência profissional.

Para a Professora 7, o maior desafio enfrentado nessa etapa da docência está relacionado com o comportamento dos alunos e a falta de envolvimento da família na educação das crianças.

[...] às vezes, eu quero que as coisas saiam muito certinho, mas, assim, no sentido de que é muito simples uma educação, é muito simples dar uma educação pra um filho e eu não me conformo de uma mãe não olhar um caderno, de uma mãe não perguntar como é que o filho está na escola. Então, esse descaso que está tendo da família com a criança, às vezes eu não consigo aceitar isso (P7).

A docente disse sentir-se incapacitada para transformar a realidade na qual atua e muito desanimada por não visualizar em seu trabalho cotidiano uma influência positiva para seus alunos, para as famílias envolvidas, como declarou: "não depende só de mim e, às vezes, eu vejo que eu ajudo aluno, ajudo, ajudo, ele vem e piora de novo. Então, eu fico desmotivada porque dá a impressão que eu não estou valendo nada, dá impressão que o meu trabalho não vale nada". Apesar de se enquadrar nessa segunda etapa da carreira, se considerados os anos de experiência, os sentimentos revelados pela entrevistada são comuns àqueles encontrados nos três primeiros anos de docência, como os desencontros entre seus ideais e a realidade escolar, como descreve HuBERMAn (2000).

A formação docente para P7 é um meio de encontrar soluções para os problemas reais do contexto educacional, além de contribuir para elevar o entusiasmo do docente.

Nossa carreira ela vai se desenvolvendo conforme o tempo, porque eu brinco que a gente... é caindo que a gente aprende, né. Mas, a formação eu diria como se fosse um amparo. É... a formação feita efetivamente, eu acho que a gente conseguiria resolver muitos problemas na área educacional, daria assim mais é... ânimo pra gente [...] porque a gente acaba ficando muito desanimado com nossos erros, desanimado com o sistema educacional, desanimado com os alunos, com a educação que eles têm agora (P7).

Já a Professora 5, há quatro anos na docência escolar, declarou que não tinha como objetivo principal dedicar-se à essa esfera profissional. Não obstante, sua atuação no ensino superior com disciplinas voltadas para a Educação Física escolar se traduziu em estímulo para que prestasse concurso com o intuito de identificar os conteúdos e outros requisitos solicitados pelo Estado para a atuação do professor dessa área e, assim, buscar uma integração entre o ensino superior e a docência no ensino básico.

[...] eu achava interessante, se eu começasse a dar aula, as contribuiçōes do ensino fundamental pra disciplina de Prática de Ensino que eu ministrava, porque era muito difícil falar da prática dos alunos sem ter a minha. Então, foi mais nesse sentido que eu quis prestar o concurso e ingressar (P5).

Nesse percurso profissional, a atuação na escola acabou acontecendo na sua vida e a satisfação com o trabalho foi encontrada no fato de poder contribuir positivamente para o desenvolvimento dos alunos: "hoje, assim, eu gosto muito de dar aula pelos alunos, pelo progresso deles, a maneira como eles vão se modificando ao longo dos anos, aquilo que eu posso contribuir com eles. Isso é fantástico", relatou a entrevistada.

Ao retratar seus sentimentos negativos com relação à educação formal, a professora enfatizou as questôes da violência, indisciplina, falta de interesse do aluno e, especialmente, a estrutura hierárquica estabelecida no sistema estadual de ensino:

$\mathrm{O}$ que me decepciona bastante é a estrutura do Estado, né. Então, toda a burocracia, uma hierarquia que você questiona muito porque eu tenho que responder a algumas pessoas que têm uma formação é... como que eu vou falar? Não é, assim, não querendo parecer arrogante, mas eu respondo a pessoas que têm muito menos tempo de estudo, muito menos interesse por estudar, que tem uma formação muito complicada, entendeu. E eu tenho que ser, eu sou subordinada a essas pessoas. Então é muito difícil você discutir com alguém que não tem conhecimento nenhum da sua área. Então, isso é uma barreira... acho que é o que decepciona a maior parte das pessoas que estão no Estado. Além de problemas como violência, como falta de disciplina, de interesse, que a gente tem e a gente passa mesmo, mas eu acho que essa parte burocrática é o mais decepcionante, assim. 
Ficou evidente no depoimento de P5 que ela está vivendo uma crise na profissão. Esse elemento HuBERMAN (2000) aponta como uma das características que surgem na fase que compreende dos sete aos 25 anos de docência (próxima etapa cronológica que a professora viverá). Mas, como adverte o autor, o fato de ter encontrado sequências-tipo em seus estudos não impede que muitas pessoas vivenciem os sentimentos mais comumente encontrados em outros momentos $\mathrm{da}$ carreira, afinal o percurso é singular à pessoa que o viveu.

A crise enfrentada por $\mathrm{P} 5$ repercute num processo de reflexão, ou seja, a faz pensar se continua ou não nessa trajetória profissional. Contou a entrevistada que, devido a essa hierarquia e aos processos burocráticos a que os professores estão submetidos no sistema de ensino estadual, não pretende continuar lecionando, mas gostaria de envolver-se com a atividades relacionadas à gestão educacional.

[...] se eu for traçar uma perspectiva pra mim no Estado, eu não acredito que eu vou continuar muito tempo em sala de aula, entendeu. Não gostaria, gostaria de ter outras possibilidades pra tentar modificar alguma coisa, porque assim, a nossa prática docente ela modifica muita coisa, mas ela não atinge essa burocracia. Então, eu gostaria de modificar alguma coisa nesse sentido.

A autonomia docente não depende exclusivamente do professor, não é intrínseco ao indivíduo e resultante de capacidades individuais somente, mas apresenta-se como um processo construído no desenrolar das situaçóes sociais (CONTRERAS, 2002).

Para a depoente, a questão primordial relacionada à formação docente está em disseminar para os professores da rede as discussões do meio acadêmico. Porém, no seu entendimento, não existe atualmente entre os envolvidos com o campo educacional a preocupação em divulgar a produção acadêmica aos que estão fazendo educação na escola. Assim como existem dificuldades por parte dos professores para articularem as produçôes teóricas com a sua prática.

\section{Fase de diversificação ou questionamentos (7-25 anos)}

Nessa ocasião o professor encontra-se num estágio de experimentação e diversificação, de motivação, de buscas de desafios. Experimenta novas práticas e diversifica métodos de ensino, tornando-se mais crítico. Pode se caracterizar, também, como uma fase de questionamentos, gerando uma crise, seja pela monotonia do cotidiano da sala de aula, seja por um desencanto causado por fracassos em suas experiências ou por reformas estruturais. O professor faz um exame do que será feito de sua vida frente aos objetivos e ideais estabelecidos inicialmente; reflete tanto sobre continuar no mesmo percurso como sobre as incertezas de uma possível mudança (HuBERMAn, 2000).

Dos depoentes participantes do estudo, três professores (P4, P6 e P8) apresentavam tempo de atuação condizente com essa etapa da carreira.

O Professor 4, com nove anos de docência, pontuou a principal dificuldade para o seu trabalho: "o difícil hoje é você conscientizar um garoto de que a Educação Física não é simplesmente correr"; mas ele acredita que no futuro próximo os alunos estarão mais conscientes "de que tem necessidade de saber a teoria antes da prática”, como abordou em suas palavras.

Sente necessidade de uma formação contínua que lhe forneça embasamentos para trabalhar com novos conteúdos, introduzidos recentemente ao currículo da disciplina:

Olha, eu gostaria de ter muito mais cursos. Poder me aprofundar mais naquilo que agora tenho necessidade que são esportes que antes não estavam dentro do currículo ou não eram trazidos para o currículo. Eu te dou um exemplo assim: hoje nós temos que trabalhar "hip-hop", "street dance", movimentos de esgrima, do boxe, e a gente sabe que isso não é aceito.

Esse professor (P4), assim como a Professora 5, não faz planos de continuar atuando com a docência na Educação Física escolar. Formou-se recentemente em Pedagogia com o intuito de mudar a sua trajetória profissional e dedicar-se a atividades de gestão escolar: "Pra futuro. Pra ser usado pra futuro porque eu não pretendo ficar na escola até acabar. É um meio pra ascensão profissional, tanto que esse ano eu já trabalhei como vice-diretor, então...", declarou.

De acordo com HuBERMAN (2000) essa característica de mudança de percurso profissional apresentada pelos depoentes P4 e P5 é típica dessa fase da carreira, em que o professor se sente motivado a buscar mais responsabilidade, autoridade e prestígio por meio do acesso a funções administrativas. Reflete-se, ainda, como a busca de novos desafios, sentindo a necessidade de comprometer-se com projetos que tenham certos significados, como foi possível notar nas preocupaçōes relatadas por P5 ("gostaria de ter outras possibilidades pra tentar modificar alguma coisa"). Sobretudo, constatou-se que a decisão de mudar o rumo da carreira está amparada no desencanto quanto ao papel de professora/professor.

Outra entrevistada, a Professora 8, também está nesta terceira etapa da carreira, com 11 anos de 
docência. Revelou em suas falas que a decisão em atuar na área educacional surgiu da necessidade de estabilidade profissional:

[...] no começo eu falei 'eu não vou pra escola, eu vou pra academia’ porque eu, já no segundo ano eu já comecei a fazer estágio, já comecei dar aula e era uma área que eu gostava, porque era ginástica, tinha um pouco da dança que eu gosto, então, eu pude ali estar satisfazendo, assim, a minha vontade de dançar. Depois eu comecei com a dança de salão que também abriu várias possibilidades e aí depois de um tempo, é... pela falta de estabilidade mesmo que a academia não oferece pro profissional, aí eu fui entrando gradativamente na escola.

Suas colocações exemplificaram a representação que alguns licenciados atuantes na academia de ginástica possuem da Educação Física escolar: para estabilizar-se profissionalmente e obterem segurança financeira buscam ingressar no sistema educacional, especialmente na esfera pública, como evidenciado em estudo de Rossi e Hunger (2008).

Quanto à fase inicial de atuação como professora, a depoente descreveu que não foi um processo fácil, passando por diferentes dificuldades.

É... no início da fase de substituto era muito difícil, porque aí eu senti mesmo a necessidade de estar buscando mais conhecimento, um aporte teórico mesmo pra, pra eu estar seguindo, que linha que eu vou seguir, o que eu julgo necessário. Então, essa mudança, né, de atuação, que eu saí de um... da academia pra um contexto totalmente diferente que é a área escolar, então, eu tive que fazer um... não sei se eu posso chamar de 'reaprender' para estar atuando na escola, estar estudando novamente os PCNs, a proposta [...] como que funcionava o Estado [...] (P8).

Ressaltou sua frustração com o comportamento dos alunos durante esse período e os questionamentos que fazia quanto à realidade que estava enfrentando: [...] a frustração do primeiro ano era você chegar lá e os alunos não fazerem a... o que você tinha colocado como objetivo da aula. Então, eu não conseguia dar aula, então eu saía realmente frustrada, 'será que o problema é comigo?', 'ou são os alunos?', 'ou é a estrutura da escola?' (P8).

Atualmente, após alguns anos de experiência, considera que é possível definir uma linha de atuação, a forma como deseja trabalhar e compreende a maneira mais adequada para atingir os objetivos educacionais, elementos descritos por HuBERMAN (2000) como comuns a esta etapa profissional. Mas, foi um processo que demandou tempo, como explicou:
[...] ao longo do tempo a gente foi percebendo [...] que tinha que dar um tempo também pros alunos acostumarem com o nosso estilo de dar aula, porque cada professor tem o seu estilo, tem a sua maneira, as suas prioridades, né, que cada um vivencia (P8).

Ao ser questionada sobre as necessidades sentidas com relação à formação continuada, a fala da depoente apontou para a importância de atualização constante para o trabalho pedagógico e para o desenvolvimento profissional:

[...] só ficar na graduação, no conhecimento que a gente teve na graduação, eu acho que prejudica nossa atuação profissional. Então, eu acredito que é importante e... acho que tudo, que sempre estão surgindo novidades e mesmo pra você é... estar por dentro do que está acontecendo, principalmente na sua área de atuação [...].

Mais um depoente, o Professor 6, encontrava-se nessa fase profissional - 21 anos de docência na área da Educação Física escolar. De acordo com seus relatos, sente-se muito desanimado com sua atuação profissional devido, especialmente, a fatores relacionados ao comportamento dos alunos, como a falta de respeito e a violência para com o professor. Têm-se, nesse caso, evidências do que Huberman (2000) pontua como o desencanto pela docência, como pode ser visto abaixo na fala do professor:

No Estado é... me desanimou muito porque com o passar dos anos a coisa tá caindo, entendeu. Os alunos não têm mais respeito, os alunos não, não têm mais paciência, entendeu. É... está difícil trabalhar, está muito difícil trabalhar. [...] você vê também outra coisa: noticiário direto de aluno batendo em professor, aluno xingando professor, aluno riscando carro de professor, aluno... Então, está difícil trabalhar, está muito difícil.

Dessa forma, o professor está decidido a mudar de atividade profissional. Pretende continuar no campo educacional, contudo ministrar aulas não faz mais parte de seus planos, seja em âmbito público estadual, seja municipal (atualmente está vinculado às duas esferas). Tem como objetivo, nesse momento, administrar uma unidade escolar privada. Seu depoimento foi incisivo: [...] comecei ano passado com uma escola particular, entendeu, é... pretendo sair fora, sair, sair fora. Tanto do Estado quanto da Prefeitura. Se eu conseguir acertar a escola lá, der certo, funcionar, eu pretendo sair. [...] Eu sou o proprietário da escola, então, eu vou trabalhar na... em cima, né. Então, nada de dar aula, pelo contrário, não quero mais saber. 
Complementou que esteve um dia muito animado com a profissão, mas para ele "caiu muito, caiu muito, muito, muito, muito. [...] Antes você trabalhava com gosto, tinha vontade, entendeu, você tinha material a vontade e os alunos te respeitavam e hoje não [...]. Está muito difícil dar aula, está muito difícil”.

As principais reclamaçóes do professor quanto à formação continuada referiram-se à ausência do Estado em desenvolver propostas efetivas de formação docente: "É uma falta de apoio, de cursos, de é... isso aí, apoio, curso e vontade, né, do Estado em fazer as coisas acontecerem [...] dá computador pro professor, dá notebook pro professor, e porque não investir em curso? [...]".

\section{Momento de serenidade e distanciamento afetivo e/ ou de conservadorismo e lamentações (25-35 anos)}

De acordo com HUBERMAN (2000), nesta ocasião o professor começa a lamentar o período passado caracterizado pelo ativismo, pela força e pelo envolvimento em desafios. Mas, em contrapartida evoca uma grande serenidade em sala de aula, certo conformismo com sua prática e se aceita como é. Tem-se um distanciamento afetivo para com os alunos que pode se dar ou pelo distanciamento gerado pelos alunos com relação aos professores mais velhos (os professores jovens são tratados por eles como irmãos(ãs) mais velhos(as)), ou, numa análise sociológica, pode resultar da pertença de professores e alunos a geraçóes diferentes, dificultando o diálogo e o envolvimento entre ambos. A fase de serenidade pode se deslocar para uma fase de conservadorismo, em que os professores se tornam mais resistentes às inovações e às mudanças e é enfatizada uma nostalgia do passado.

Dentre os participantes desse estudo, o Professor 2 é o mais experiente, completando no momento da coleta das entrevistas 30 anos de docência. Encontrava-se, pelo critério do tempo de trabalho, nessa etapa da carreira. Mas o professor já estava se preparando para a aposentadoria, a fase de desinvestimento profissional, a qual HUBERMAN (2000) indica que acontece, geralmente, entre os 35-40 anos de vida profissional. Para P2 esse acontecimento se antecipou em alguns anos, o que não surpreende, reforçando que as etapas da carreira encontradas pelo autor não são rígidas, podendo haver variaçôes com relação ao contexto que o docente está inserido.

O professou contou sobre o início da carreira docente e relatou as principais dificuldades enfrentadas:
[...] no começo [...] eu fui para uma cidade que nem quadra eu tinha. Então, eu não posso falar assim que eu tinha uma bola, porque não tinha, nem quadra eu tinha. Era chão batido, era saibro batido. A quadra quem fez fui eu. Arrumamos com a Prefeitura um menino lá, fizemos o alicerce. Quer dizer, então, eu realmente comecei a carreira lá de baixo, da quadra, né. Tinha uma boa formação, porque a nossa faculdade na época era muito forte, era uma faculdade excelente [...], então nós fomos preparados, sabe. Só que no começo é assim, tem aquele negócio de você ser profissional, trabalhar. Só que eu deparei com um lugar, com uma escola sem quadra, sem nada, tive que começar do zero, sabe.

Apesar dos desafios, o professor citou que nunca desanimou: "mas nunca desanimei não, não foi pela falta de material, sempre trabalhei bem, nunca tive problema com escola”. Hoje, sua visão do ambiente escolar é mais negativa, perpassando a falta de apoio dos envolvidos com o campo educacional o desrespeito dos alunos:

[...] agora piorou, né, porque além de tudo isso aí você tem a falta de apoio. Não aqui. Aqui tem uma direção boa, quando você chama atenção te apoia. Se precisar de alguma coisa, material a gente tem o suficiente pra trabalhar direitinho, mas a gente sabe que tem lugar que nem isso tem. Tem colegas da gente que passa isso e eu sei o que é passar tudo isso. Agora, cada vez o alunado vai ficando pior, tem aquelas escolas cada vez pior. Você... não te respeitam mais. A aula de Educação Física que é o xodó, ainda continua sendo o xodó, você tem que brigar com eles de vez em quando, você tem que encarar eles porque eles não te obedecem, não cooperam. Você tem que impor, às vezes, ser um pouco mais agressivo, pra poder manter um pouco de disciplina.

O professor declarou o descontentamento quando outras pessoas lhe dizem que essa sua opinião é resultado da proximidade com a aposentadoria, sugerindo o seu desinteresse pela profissão. No entanto, afirmou que "não é porque está em fim de carreira, mas é que vai magoando, né, eu fico chateado. Então, eu acho que pra quem está começando agora, vai ser duro. Eu acho, eu acho”. Assim, revelou-se na narrativa do docente uma nostalgia do passado.

As maiores dificuldades em termos de formação continuada para o professor estão relacionadas com a impossibilidade de se ausentar da escola para participar de práticas dessa natureza: "se tiver um curso e se você for pedir pra ser dispensado, você não vai 
ser, você não vai ser." Sua principal crítica consiste na falta de oportunidade para desenvolver-se por meio da formação: "se tivesse, por exemplo, cursos a noite que a gente pudesse fazer, mas faz muito tempo que eu não vejo nada nesse sentido".

Como está em fase de desinvestimento da carreira, o professor está planejando outras atividades para quando aposentar-se da escola: pretende investir em uma academia de ginástica em sociedade com seu filho, também formado em Educação Física. Essa postura é observada por HUBERMAN (2000) como predominante da fase de desinvestimento, recuo $e$ interiorização (35-40 anos). Geralmente, nessa fase é tomada uma postura positiva face ao desinvestimento profissional, libertando-se progressivamente do trabalho sem lamentaçôes para dedicar mais tempo a si próprio e a outros interesses extra-escolares, como revelou o docente entrevistado. Contudo, professores que não tenham alcançado seus objetivos, suas ambiçôes iniciais, podem caminhar para o desinvestimento na sua vida profissional ainda no período de desenvolvimento da carreira. Enfim, tal fase pode acontecer de modo sereno ou amargamente (Huberman, 2000).

\section{Considerações finais}

Do problema norteador da pesquisa, em que se consistiu responder se as necessidades formativas em cada período profissional são as mesmas para os professores, evidenciou-se pelos depoimentos orais que estes apresentam necessidades e expectativas diferentes em cada momento da carreira docente. Pôde-se verificar que na fase de entrada na carreira, os depoentes revelaram buscar ações formativas para aprimorar a prática pedagógica e diminuir o choque com o real dessa fase profissional. Já na fase de estabilização, os professores disseram que ações dessa natureza são importantes para solucionar os problemas do contexto educacional, assim como disseminar os conteúdos acadêmicos entre os professores escolares. Os professores que se encontravam na fase de diversificação relataram que o embasamento para trabalhar novos conteúdos e atualização constante diante das novidades que surgem a todo o momento no campo educacional são suas prioridades de formação e, por fim, no momento de serenidade/ desinvestimento a necessidade traduz-se em frequentar atividades formativas em espaços diferentes da escola para inovar suas práticas cotidianas.

Portanto, confirmou-se a hipótese de que as prioridades de formação variam de acordo com o decorrer da carreira assim como ocorre com outros fatores profissionais, conforme discutidos na introdução e no decorrer desse artigo. Acredita-se que os resultados encontrados, a partir da análise dos fatores específicos à dimensão da formação continuada evidenciados em cada etapa da carreira docente, complementam o referencial teórico dos ciclos de vida profissional desenvolvido por HUBERMAN (2000).

As novas tendências em formação continuada vislumbram um professor capaz de apropriar-se de um pensamento autônomo, baseando-se na reflexão de todo o processo que envolve suas ações docentes e nas experiências advindas da sua prática cotidiana, e capaz de atuar como principal agente da formação, assumindo-se como sujeito do seu desenvolvimento e na construção da sua profissionalidade docente. Como ressalta IMBERNÓN (2009) é preciso que as ações sejam pautadas na cultura profissional, pois esta atua como espécie de filtro interpretativo da realidade. Faz-se necessário um trabalho conjunto dos diferentes atores educacionais com o intuito de solucionar as situaçóes problemáticas das práticas educativas, bem como (re) construir constantemente a identidade docente.

As considerações apresentadas nesse estudo não tiveram a pretensão de produzir generalizações, mas sim delinear um espaço que possa contribuir para que os leitores façam as associações com sua realidade, de acordo com suas experiências e contextos de atuação. $\mathrm{O}$ que se pôde concluir, a partir das análises dos relatos, foi que a formação contínua contribui para a constituição da profissionalidade docente, uma vez que os professores reconhecem a sua importância, ressaltando as influências para a vida profissional.

Ressaltam-se as colocações de NóvOA (1999) ao declarar que é impossível imaginar alguma mudança educativa que não passe pela formação de professores. Mas isso significa, sobretudo, mudar a concepção de formação, situando o desenvolvimento pessoal e profissional dos professores ao longo dos diferentes ciclos da sua vida, construindo lógicas de formação que valorizem a sua experiência em todas as fases: aluno, aluno-mestre, estagiário, professor principiante, professor titular e, inclusive, professor reformado.

Diante do exposto, é imprescindível reconhecer que a formação continuada é um processo heterogêneo, 
sendo preciso considerar todas as variantes envolvidas, como as necessidades e as expectativas dos professores em cada momento do exercício profissional, como enfatiza CANDAU (1997). Soma-se a isso o contexto social e local como elemento necessário, de modo que o trabalho coletivo de professores, agentes formadores, pesquisadores, gestores etc., viabilize processos próprios de intervenção formativa, correspondendo de forma mais adequada ao momento histórico vivido pelos professores.

\title{
Notas
}

1. Artigo resultante de dados parciais, especialmente, das entrevistas coletadas com um grupo de professores durante o desenvolvimento da dissertação de Mestrado intitulada "Formação continuada em Educação Física escolar: concepções e perspectivas de professores" defendida no Programa de Pós-graduação em Ciências da Motricidade, sob orientação da Profa. Adja. Dagmar Hunger em 2010. Apoio: CNPq.

Apoio: CNPq, FAPESP.

Fernanda Rossi é bolsista FAPESP e Dagmar Hunger é bolsista produtividade CNPq PQ-2.

\begin{abstract}
Stages of teaching career and the process of continuing education of Physical Education teachers

In this research, qualitative, aimed to analyze the meanings assigned by Physical Education teachers to the relationship between continuing education and professional development stages. Semi-structured interviews were conducted with eight state public school teachers of Bauru/SP. The data were analyzed following the theory referential of HUBERMAN (2000), relatively to the concept of professional life cycles, and found that as well as other factors of the teaching career, on the extent of continuing education teachers also have different needs at each moment professional. In summary concluded: the early stage to teaching, they seek activities to improve pedagogical practice; stabilization phase: to solve problems in the educational context and to disseminate the academic content between teachers; diversification phase: to provide a basis to work new content and to make constant updates according to educational innovations; serenity/exit: they feel the need to attend training activities in different spaces of the school.
\end{abstract}

UnITERMs: Teacher education; Professional development cycles; Physical education in the school.

\section{Resumen}

Etapas de la carrera docente y el proceso de formación continua de los profesores de Educación Física

Esta investigación, de naturaleza cualitativa, tuvo como objetivo analizar los significados asignados por los profesores de educación física en la relación entre formación continua y medidas de desarrollo profesional. Entrevistas semiestructuradas se realizaron con ocho maestros de escuelas públicas en Bauru / SP. Los datos fueron analizados siguiendo el marco teórico de HuBerman (2000), por el concepto de ciclo de vida, y se encontró que al igual que con otros factores de la carrera docente, en la medida de los maestros de educación continua también tienen necesidades de trabajo diferente en cada momento profesional. En resumen, llegamos a la conclusión: en la etapa de iniciación los docentes buscan actividades de capacitación para mejorar la práctica docente; fase de estabilización: la solución de problemas del contexto educativo y para difundir el contenido académico de los maestros de escuela; fase de diversificación: las bases para un nuevo contenido a trabajar y actualización constante de noticias 
sobre la educación, la serenidad / desinversión: la necesidad de asistir a las actividades de capacitación en diferentes espacios de la escuela.

PalABRAS Clave: Formación del profesorado; Los ciclos de desarrollo profesional; La educación física.

\section{Referências}

AMADO, J.; FERREIRA, M.M. (Orgs.). Usos \& abusos da história oral. Rio de Janeiro: Fundação Getúlio Vargas, 1996. ANDRÉ, M.E.D.A. Formação de professores em serviço: um diálogo com vários textos. Cadernos de Pesquisa, São Paulo, n.89, p.72-5, 1994.

BUENO, B.O. Pesquisa em colaboração na formação contínua de professores. In: BUENO, B.O.; CATANI, D.B.; SOUSA, C.P. (Orgs.). A vida e o ofício dos professores: formação contínua, autobiografia e pesquisa em colaboração. São Paulo: Escrituras, 1998. p.7-20. CANDAU, V.M. Formação continuada de professores: tendências atuais. In: (Org.). Magistério: construção cotidiana. Petrópolis: Vozes, 1997. p.51-68.

CAVACO, M.H. Ofício do professor: o tempo e as mudanças. In: NÓVOA, A. (Org.). Profissão professor. 2. ed. Porto: Porto, 1999. p.155-91.

CHAKUR, C.R.S.L. (Des)profissionalização docente e formação continuada: situação e perspectivas atuais. In: LEITE, C.D.P.; OLIVEIRA, M.B.L.; SALLES, L.M.F. (Orgs.). Educação, psicologia e contemporaneidade. Taubaté: Cabral Ed. Universitária, 2000. p.71-89.

O desenvolvimento profissional de professores das séries iniciais do ensino fundamental. Paidéia, Ribeirão Preto, v.15, n.32, p.397-407, 2005.

CONTRERAS, J. A autonomia de professores. São Paulo: Cortez, 2002.

DEMO, P. Professor e seu direito de estudar. In: SHIGUNOV NETO, A.; MACIEL, L.S.B. (Orgs.). Reflexóes sobre a formação de professores. Campinas: Papirus, 2002. p.71-88.

Professor do futuro e reconstrução do conhecimento. In: MACIEL, L.S.B.; SHIGUNOV NETO, A. (Orgs.).

Formação de professores: passado, presente e futuro. São Paulo: Cortez, 2004. cap. V, p.113-27.

ELIAS, N. Introdução à sociologia. Tradução Maria Luísa Ribeiro Ferreira. São Paulo: Martins Fontes, 1980.

FERREIRA, L.A. O professor de educação física no primeiro ano da carreira: análise da aprendizagem profissional a partir da promoção de um programa de iniciação à docência. 2005. 216f. Tese (Doutorado em Educação) - Faculdade de Educação, Universidade Federal de São Carlos, São Carlos, 2006.

GIMENO SACRISTÁN, J. Tendências investigativas na formação de professores. In: PIMENTA, S.G.; GHEDIN, E. (Orgs.). Professor reflexivo no Brasil: gênese e crítica de um conceito. São Paulo: Cortez, 2002. p.81-7.

GÜNTHER, M.C.C.; MOLINA NETO, V. Formação permanente de professores de educação física na rede municipal de ensino de Porto Alegre: uma abordagem etnográfica. Revista Paulista de Educação Física, São Paulo, v.14, n.1, p.85-91, 2000. HUBERMAN, M. O ciclo de vida profissional dos professores. In: NÓVOA, A. (Org.). Vidas de professores. 2. ed. Porto: Porto, 2000. p.31-61.

IMBERNÓN, F. Formação permanente do professorado: novas tendências. São Paulo: Cortez, 2009.

LIBÂNEO, J.C. Reflexividade e formação de professores: outra oscilação do pensamento pedagógico brasileiro? In: PIMENTA, S.G.; GHEDIN, E. (Orgs.). Professor reflexivo no Brasil: gênese e crítica de um conceito. São Paulo: Cortez, 2002. p. 53-79. MARCELO GARCÍA, C. A formação de professores: novas perspectivas baseadas na investigação sobre o pensamento do professor. In: NÓVOA, A. (Org.). Os professores e a sua formação. Lisboa: Dom Quixote, 1995. p.51-76.

Formação de professores: para uma mudança educativa. Porto: Porto, 1999.

MARIN, A.J. Educação continuada: introdução a uma análise de termos e concepções. São Paulo: Papirus, 1995. (Cadernos CEDES 36: Educação Continuada, p.13-20).

MEDIANO, Z.D. A formação em serviço de professores através de oficinas pedagógicas. In: CANDAU, V.M. (Org.). Magistério: construção cotidiana. 4. ed. Petrópolis: Vozes, 1997. p.91-109.

MINAYO, M.C.S. (Org.). Pesquisa social: teoria, método e criatividade. Petrópolis: Vozes, 2001.

MOREIRA, H.R.; NASCIMENTO, J.V.; SONOO, C.N.; BOTH, J. Qualidade de vida no trabalho e perfil do estilo de vida individual de professores de educação física ao longo da carreira docente. Motriz, Rio Claro, v.16 n.4, p.900-12, 2010. NÓVOA, A. Notas sobre formação (contínua) de professores. [S.l: s.ed.], 1992. (Mimeografado). 
ROSSI, F. \&HUNGER, D.

Formação de professores e profissão docente. In: (Org.). Os professores e a sua formação. 2. ed. Lisboa: Dom Quixote, 1995. p.15-33.

. Os professores na virada do milênio: do excesso dos discursos à pobreza das práticas. Revista Educaçáo e Pesquisa, São Paulo, v.25, n.1, p.11-20, 1999.

Os professores e as histórias da sua vida. In: (Org.). Vidas de professores. 2. ed. Porto: Porto, 2000. p.11-30. PERRENOUD, P. Práticas pedagógicas, profissão docente e formação: perspectivas sociológicas. 2. ed. Lisboa: Dom Quixote, 1997.

PIÉRON, M. Formação de professores: aquisição de técnicas de ensino e supervisão pedagógica. Lisboa: Faculdade de Motricidade Humana, 1996.

PIMENTA, S.G. Professor: formação, identidade e trabalho docente. In: (Org.). Saberes pedagógicos e atividade docente. 2. ed. São Paulo: Cortez, 2000. p.15-35.

RANGEL-BETTI, I. C. Os professores de educação física atuantes na educação infantil: intervenção e pesquisa. Revista Paulista de Educação Física, São Paulo, p.83-94, 2001. Suplemento 4.

ROSSI, F.; HUNGER, D.A.C.F. Formação acadêmica em educação física e intervenção profissional em academias de ginástica. Motriz, Rio Claro, v.14, n.4, p.440-51, 2008.

TARDIF, M. Saberes docentes e formação profissional. Petrópolis: Vozes, 2002.

THOMPSON, P. A voz do passado. 2. ed. Rio de Janeiro: Paz e Terra, 1992.

VASCONCELLOS, C.S. Coordenação do trabalho pedagógico: do projeto político-pedagógico ao cotidiano da sala de aula. 5. ed. São Paulo: Libertad, 2004.

VIGOTSKI, L.S. A formação social da mente. São Paulo: Martins Fontes, 1988.

\begin{tabular}{r|r} 
ENDEREÇO & \\
Fernanda Rossi & $\begin{array}{r}\text { Recebido para publicação: 01/ 08/2011 } \\
\text { Revisado: 02/03/2012 } \\
\text { R. Sebastião Aparecido Alves de Lima, 40 - apto. 32 - bloco I } \\
\text { 13482-357 - Limeira - SP - BRASIL } \\
\text { e-mail: fernandarossi_ef@hotmail.com }\end{array}$
\end{tabular}

